DIVISION OF THE HUMANITIES AND SOCIAL SCIENCES

CALIFORNIA INSTITUTE OF TECHNOLOGY

PASADENA, CALIFORNIA 91125

ECONOMICS, ENTITLEMENTS AND SOCIAL ISSUES: VOTER CHOICE IN THE 1996 PRESIDENTIAL ELECTION

R. Michael Alvarez

California Institute of Technology

Jonathan Nagler

University of California, Riverside

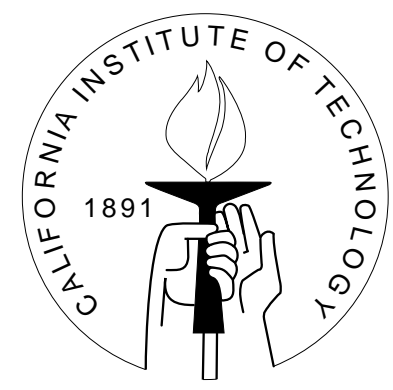

SOCIAL SCIENCE WORKING PAPER 1021 


\title{
Economics, Entitlements and Social Issues: Voter Choice in the 1996 Presidential Election
}

\author{
R. Michael Alvarez Jonathan Nagler
}

\begin{abstract}
Theory: Contemporary theories of presidential election outcomes, especially the economic voting and spatial issue voting models, are used to examine voter choice in the 1996 presidential election.

Hypotheses: First, we look at the effects of voter perceptions of the national economy on voter support for Clinton. Second we look at the effects of candidate and voter positions on ideology and on a number of issues. Last, we examine whether respondents' views on other issues - social issues such as abortion as well as issues revolving around entitlements and taxation that were emphasized by the campaigns - played significant roles in this election.

Methods: Multinomial probit analysis of the 1996 National Election Studies data; simulations based on counterfactual scenarios based on different macroeconomic conditions and different issue platforms of candidates.

Results: The effects of economic perceptions are much greater than the effects of voter issue positions on the election outcome. Some social issues, namely abortion, did play a role in determining the election outcome. The presence of a third centrist candidate limited the ability of other candidates to improve their vote shares by moving in the issue space.
\end{abstract}




\title{
Economics, Entitlements and Social Issues: Voter Choice in the 1996 Presidential Election*
}

\author{
R. Michael Alvarez Jonathan Nagler
}

\section{Introduction}

For almost the last half-century, academic interest has focused on the determinants of presidential election outcomes. In general, both scholarly and popular discussions of presidential election outcomes has focused on three causal factors: the state of the economy, the positions of voters and candidates on the issues, and on the ability of candidates to conduct effective campaigns for office. In this paper we seek to understand how these different factors account for the outcome of the 1996 presidential election; in turn, this will better help in our general understanding of how voters make their decisions in American presidential elections.

In recent years, much interest has focused on the importance of the national economy as a significant factor in accounting for both the success of three Republican presidential candidates during the 1980's as well as Bill Clinton's first victory in 1992 (Alvarez and Nagler 1995; Fiorina 1981; Kiewiet 1983; Markus 1988; Rosenstone 1983; Tufte 1978). But at the same time, many in academic and popular circles have pointed to a number of non-economic factors as potentially important features of presidential politics. For example, in recent years social issues may have risen in importance as factors in presidential politics, most especially the issues of abortion and voter anger with Washington and the federal government. Social issues are not new to American presidential elections; George McGovern was tagged with the '3 A's' - Amnesty, Abortion, and Acid — in 1972. But what is perhaps new are the organizational resources devoted to social issues associated with the rise of the right-wing of the Republican party. Contrasting the cultural set of social issues, in the 1990s the Democrats adopted a strategy of trying to make entitlement

*This is one of many joint papers by the authors on multiparty elections, the ordering of their names reflects alphabetic convention. We thank Alan Abramowitz, Tara Butterfield, and Garrett Glasgow for their comments. A previous version of this paper was presented at the Annual Meeting of the American Political Science Association, Washington, DC, August, 1997. This work was supported by National Science Foundation grants SBR-9709327 to Alvarez, and SBR-9413939 and SBR-9709214 to Nagler. Comments may be directed to the authors at: DHSS 228-77, California Institute of Technology, Pasadena, Ca 91125, Internet: rmacrunch.caltech.edu; and Department of Political Science, University of California, Riverside, Ca 92521-0118, Internet: naglerwizard.ucr.edu, respectively. 
programs an issue: arguing to voters that Republicans would eliminate or severely curtail Medicare and Social Security if given the opportunity. In addition to specific issues, the more general notions of liberal and conservative ideology have been seen as important issues in presidential campaigns since Ronald Reagan ran on an ideological position distinct from his opponent. Since then presidential elections have featured George Bush's attacks on Michael Dukakis's liberalism in the 1988 campaign and Clinton's more recent "New Democratic" ideology. So there are strong reasons to believe that both issues and ideology were important factors in the 1996 presidential election as they have been in previous elections (Abramson et al. 1983, 1987, 1990, 1994; Carmines and Stimson 1980; Jackson 1975; Key 1966; Page and Brody 1972; Pomper 1972).

While it is important to understand the relative impacts of economics, issues and ideology in particular presidential elections, having a general sense of which factors tend to matter most in voter decision rules can produce normative conclusions about the quality of voter decisions and whether politicians face serious constraints while in office. Judgments about presidential candidates based on retrospective economic concerns might be seen as employing objective and tangible information. However, if presidents have little control over short-term macroeconomic importance, retrospective economic evaluations might be poor decision criteria for voters to employ in electoral choice if their goal is to insure outcomes they desire. Thus, if voters are using economic criteria and not issue or ideological information in their decisions, candidates might be allowed much more flexibility in their future policymaking activities than voters would like them to have.

Another reason we find the 1996 presidential race to be of particular interest is the presence of Ross Perot as a non-major party candidate. While in 1992 Perot received almost $20 \%$ of the popular vote, in 1996 his popular vote was cut in half. Despite a number of accounts for Perot's showing in the 1992 election (Abramson et al. 1995; Alvarez and Nagler 1995; Zaller and Hunt 1994), it is important to determine what factors drove Perot's support to less than 10\% in 1996. Studying presidential elections when there are three potentially viable candidates is both theoretically and methodologically challenging. A three-candidate presidential race is more difficult to model theoretically and empirically since the assumptions in both the standard two-candidate theoretical models of elections and the simple methodological techniques used to study two-candidate races (usually logit or probit models) may be incorrect and inferences drawn from them could be error-prone. The retrospective model of voting can be inadequate if it does not allow us to predict which of the two non-incumbent parties a voter will choose. Here we use a relatively new methodological technique, multinomial probit, to study this threecandidate race which minimizes the restrictive assumptions we need to make in order to estimate a model of voter choice.

In this paper we examine three sets of explanations for the outcome of the 1996 presidential election campaign. First, we look at the effects of voter perceptions of the national economy on voter support for Clinton. Second we look at the effects of candidate and voter positions on ideology and on a number of issues on support for the candidates. Third, we seek to understand whether voters' positions on other issues — social issues 
such as abortion as well as issues revolving around entitlements and taxation that were the focus of indirect and direct campaign strategies - played significant roles in this election. Thus this work extends the work of Alvarez and Nagler (1995) and enriches it with analysis of a more comprehensive set of issues. In the end, we are able to pull together each of these different sets of explanations into a consistent analysis of the 1996 presidential election which shows why Clinton won this race, and which also helps us understand why it was that both Dole and Perot fell so far from electoral victory. This allows us to more fully understand the relative importance of economics and issues in determining presidential election outcomes.

\section{A First Look at the Data}

Before turning to a multivariate analysis of voter choice in the 1996 presidential election, we first present the choices made by voters amongst the three major candidates, broken down by several important factors. Then we turn to a simple presentation of ideological positioning data which is designed to examine the support in the survey data for the idea that Clinton's ideological stance as a "New Democrat" was important. In Table 1 we provide a simple crosstabulation showing the relationship between support for each of the three major candidates (Perot, Dole, and Clinton) and the voters' perceptions of the economy, their partisanship, gender and past voting behavior. We also examine the bivariate relationship between candidate support and a number of measures of voter preferences on social and entitlement issues. The data is from the 1996 American National Election Study (Rosenstone, Kinder, and Miller 1996).

\section{Table 1 Goes Here}

We first examine the voters' perceptions of both their own personal finances and the national economy in the past year and how that is related to their candidate preferences. ${ }^{1}$ First, of those voters who thought their own personal financial situation had worsened in the past year, most were Dole supporters (47\%) but not by a great margin over Clinton, since $44 \%$ of those who believed their own financial situation had worsened over the past year voted for Clinton. This low margin is interesting because Clinton was much more successful with this group of voters in his 1992 challenge. Clinton received the votes of $58.1 \%$ of voters who felt the economy was worse off in 1992, while Bush retained only 21.5\% of these voters (Alvarez and Nagler 1995). When we look to the voters who found that their personal financial situation had improved in the past year we see they are overwhelming supporters of Clinton (62\%). Second, the effects of retrospective evaluations of the national economy seem to have an even stronger effect on candidate preference than do retrospective evaluations of personal finances in Table 1, which is consistent with the conventional wisdom (Kinder and Kiewiet 1981). We see that those voters who believed that the national economy had grown much worse in the past year were very likely to be Dole voters (57\%) and even a sizable number of these voters supported Perot (13\%). The situation reverses itself when we look to those who believed that the national economy had gotten better in the past year: fully $71 \%$ of those voters supported Clinton, $23 \%$ 
supported Dole, and only 6\% supported Perot. Therefore, from these simple bivariate comparisons we have strong support for the hypothesis that perceptions of the national economy and a voter's personal financial condition were important determinants of voter choice in this presidential election.

We provide next in Table 1 the breakdown of vote choice based on partisanship, past political participation, and gender. Not surprisingly, professed Republicans were strong supporters of Dole (79\%); however 21\% of the stated Republicans "defected" to support Clinton (14\%) or Perot (7\%). Clinton was not only able to draw significant support from stated Republicans, but he was able to keep Democrats from "defecting" to a much larger extent - Clinton received the votes of $88 \%$ of the Democrats in our sample, a full nine percent lower defection rate than Dole could maintain. This was also $18 \%$ higher than Bush's retention rate of Republicans in 1992 when only $70 \%$ of Republicans voted for Bush (Alvarez and Nagler 1995). Last, while stated independents roughly split between Clinton and Dole, many independents (20\%) supported Perot's third party candidacy.

One popular account for the role of third party candidates is that they serve to mobilize disaffected citizens who would otherwise tend to stay home on election day. We find little support for any sort of strategic mobilization effect on new voters by Perot. Of those who did not vote in the 1992 presidential election, but voted in 1996, most actually supported Clinton (58\%). This is actually higher than Clinton's 53\% rate of support among those who had voted in 1992. Thus it seems that as in the 1992 election, Perot did not mobilize large groups of alienated and disaffected voters to enter the political process.

Next, evidence for the well-documented gender gap in support for presidential candidates is provided in Table 1 . Male voters were slightly more inclined to support Clinton than Dole (a difference of roughly $2 \%$ ). But female voters were vastly more likely to vote for Clinton than for Dole, with $60 \%$ of the females in our sample supporting Clinton and only $34 \%$ supporting Dole. This gender gap of $24.1 \%$ could have been driven largely by the differences in preferences on social and economic issues, and probably by differences in partisanship, between men and women (Chaney et al. 1997). Men were slightly more likely to vote for Perot than women, continuing a pattern observed in the 1992 election (Alvarez and Nagler 1995).

Next we provide the breakdown of candidate support by respondents' positions on three important issues where the major candidates had clearly distinct positions: abortion, welfare and social security cuts. We see in Table 1 that pro-life voters were strong supporters of Dole (55\%) while pro-choice voters were strong supporters of Clinton (68\%). This was very similar to 1992, since in that election $48 \%$ of pro-lifers supported Bush and $57 \%$ of the pro-choice voters supported Clinton (Abramowitz 1995; Alvarez and Nagler 1995). Perot's support does not appear to vary much among the different camps of opinion. We find similar patterns when we look at both welfare and social security cuts: those who wished to see cuts in either entitlement program were strong supporters of Dole ( $52 \%$ and $69 \%$ respectively). Those who wanted the programs increased were 
strong supporters of Clinton (84\% and 66\%, respectively).

One of the issues emphasized by the Dole campaign was the $15 \%$ tax cut. $67 \%$ of those who favored at least a 15\% tax cut voted for Dole. Of those who opposed such a tax cut, most voted for Clinton (54\%). Surprisingly, for a candidate who had campaigned on the issue of the federal budget deficit in the previous election, those who opposed the $15 \%$ tax cut were only slightly more likely to support Perot than those who favored the $15 \%$ tax cut.

\subsection{Did the Electorate see Clinton as a Moderate?}

One of the major accounts for both of Clinton's presidential election victories focuses on the overall ideological position of the candidates. Conventional wisdom has asserted that Clinton's efforts to define himself and his party as "New Democrats" were largely successful and were a large part of Clinton's ability to win in 1992 and 1996. Alvarez and Nagler cast considerable doubt on the "New Democrat" hypothesis, largely since they were able to show that American voters did not seem to see Clinton as an ideological moderate (Alvarez and Nagler 1995). In Table 2 we update the data presented in Alvarez and Nagler's 1995 paper. Here we give the mean ideological placements for voters and the Republican and Democratic presidential candidates for 1988, 1992, 1994 and 1996. ${ }^{2}$ We also give the mean ideological placement for Perot in 1992-96. Last we compute the average distance between the voters in our sample and each candidate.

\section{Table 2 Goes Here}

We see in the first row of Table 2 that the American electorate in 1994 was ideologically similar to the electorate in 1992, but the ideological distribution of voters shifts slightly to the right in 1996. Thus, the American electorate was slightly more conservative in 1996 than in the previous two elections. Turning to the candidate's positions over these elections, we see a remarkable amount of similarity — not change. While voters saw Bush as slightly more liberal in 1992 than 1988, they saw Dole as slightly more conservative in 1996 than Bush. Yet since in 1996 voters were slightly more conservative than in 1992, Dole was actually no closer or further from most voters than Bush had been in 1992.

Clinton, though, had been seen in 1992 as more liberal than Dukakis had been in 1988. After the significant political events in the first two years of Clinton's first administration, we might have expected that the voters could have learned more about Clinton's "New Democratic" policies — and hence voters should have seen Clinton as being more conservative in 1994 than in 1992. Yet we observe exactly the opposite in Table 2; Clinton was seen as slightly more liberal in 1994 and 1996 than in 1992. With the electorate becoming slightly more conservative in 1996 than in 1992, this actually implies that Clinton was slightly further from the electorate in 1996 than he had been in earlier elections. Thus there seems to be little support for the assertion that Clinton was seen as a moderate, "New Democrat" since in each of the three election years 1992-1996 voters saw Clinton as more liberal than they had seen Mike Dukakis. 
In the last two rows of Table 2 we give the same information for placement of Perot. One important observation to begin with regarding Perot's positioning is that between 1992 and 1996 he is always between Clinton and the two Republican presidential candidates in the ideological space. We see a slight movement in Perot placement to the right, between 1992 and 1996. Perot was seen as somewhat more conservative in 1996 than in 1992. But again, since the electorate became somewhat more conservative between 1992 and 1996 as well, this means that Perot was actually in roughly the same location relative to most voters in 1996 as he had been in 1992 .

\section{Multivariate Analysis of the 1996 Presidential Elec- tion}

It is impossible to differentiate amongst the competing explanations for Clinton's 1996 reelection by looking only at bivariate relationships. To better test these different explanations requires a multivariate methodology which will give us the ability to determine the relative effects of respondent characteristics and candidate position on issues in a three-candidate election. We want to use the multivariate model which imposes the fewest restrictions; therefore we use the multinomial probit model to produce multivariate estimates of the relative effects of these many different factors on vote choice in the 1996 presidential election (Alvarez and Nagler 1995, 1997).

The multinomial probit model we use here is very similar to the model used in Alvarez and Nagler's analysis of the 1992 election (Alvarez and Nagler 1995). ${ }^{3}$ Following standard practice (Alvarez and Nagler 1995, 1997; Hausman and Wise 1978) we define the random utility for each voter for the three candidates in the 1996 election as:

$$
U_{i j}=a_{i} \Psi_{j}+X_{i j} \beta+\varepsilon_{i j}
$$

where $U_{i j}$ is the utility of the $j^{\text {th }}$ candidate to the $i^{\text {th }}$ voter, $a_{i}$ is a vector of characteristics unique to each individual voter $i, X_{i j}$ is a matrix of characteristics $k$ unique to candidate $j(j=1,2,3)$ with respect to each voter, $\Psi_{j}$ and $\beta$ are coefficient vectors and $\varepsilon_{i j}$ is a disturbance term. As is usually the case with random utility models, we assume that individuals vote for the candidate who brings them the highest utility. Under the multinomial probit model we assume that the three disturbance terms are distributed multivariate normal. Last, we assume that the three diagonal elements of the error variance-covariance matrix (the three error variances) are homoskedastic, a normalization which allows us to estimate various remaining error covariances. ${ }^{4}$

In this multinomial probit specification, we estimate one coefficient for each alternative characteristic; thus we estimate only one parameter for each of the issue and ideological distance measures we have in our model. But, for individual characteristics, we estimate $(J-1)$ coefficients for each characteristic, with $J$ being the number of choices in the model. Since there are only three choices in the model we present below, that means we will estimate two coefficient vectors. One of these sets of coefficients gives 
the effect of a particular individual characteristic on the relative choice of Clinton and Perot; the other set of coefficients gives the effect of an individual characteristic on the relative choice of Dole and Perot.

The data we use to estimate the model is the same we used in Table 1: the 1996 American National Election Study (Rosenstone, Kinder, and Miller 1996). In their work on the 1992 election, Alvarez and Nagler were only able to operationalize ideological distance between the three candidates and each voter, since there was no issue placement information for Perot in the 1992 study (Alvarez and Nagler 1995). In the 1996 data, however, respondents in the first two (of four) sample replicates were asked to place Perot on a wide range of seven point issue scales (government services, defense spending, government responsibility for jobs, aid to blacks, crime reduction, and environmental regulation); the entire sample was asked to place Perot on the ideological scale. Thus we are able to model a number of different candidate-specific variables. Below we first estimate a model which essentially replicates Alvarez and Nagler's model of the 1992 election, with only the ideological distance of the voter from each candidate. We then estimate a second model which contains ideological distance and all of the issue distances just listed. The measure of ideological or issue distance we employ is the squared difference between the respondent's self placement on the respective NES seven point issue or ideological scale and the candidate's mean placement on the same scale by all of the survey respondents. ${ }^{5}$

Each of the measures in Table 1 are included in the model as individual-level characteristics. Thus, we have included measures of the respondent's opinion of the change in their personal finances over the past year and their opinion on the change in the national economy during that same time. Both of these measures are coded with positive evaluations as the high category. We include measures for opinions on whether both welfare and social security should be increased, kept the same, or cut (both variables were coded in that order — with the conservative answers the higher values). We also included opinions on the Dole 15\% tax cut (a binary variable coded such that agreement with Dole on this issue was the high category). Additionally we include the respondent's opinion of government health insurance (conservative answers were coded high on the seven point scale). Last we measured respondents' opinions about abortion policy by using responses from a question which asked respondents which of four abortion options best represented their beliefs on abortion policy, with pro-choice coded high.

We also include a series of other measures which measure individual characteristics which might have influenced voter choice in the 1996 presidential election. We have dummy variables for Republican and Democratic identification (with independents being the baseline category). Also, there are measures for the respondent's educational attainment (years of schooling), gender (females were coded high), age (three dummy variables), and region (dummy variables for West, South and East).

This specification of our multinomial probit models provides us with the means to test competing propositions concerning the determinants of voter choice in the 1996 
presidential election. We use our estimates of the effects of economic perceptions to understand how important the economy was in this presidential election. The estimates on our ideological distance and issue distance variables give us the tools we need to understand the effects of spatial placement of voters and candidates. Last, our estimates of the effects of social, entitlement and taxation issues give us the ability to examine these other explanations for voter choice in the 1996 presidential election campaign.

\subsection{Multinomial Probit Estimates of the 1996 Election}

In Table 3 we present the multinomial probit estimates of our model which includes the ideological distance measure but not the specific issue distances. This model basically serves to replicate Alvarez and Nagler's model of the 1992 election (Alvarez and Nagler 1995). In Table 4 we include the issue distance measures as well as the ideology measure. ${ }^{6}$ In each table, the parameter estimates in the left column give the coefficients which express the effect of each individual characteristic on the likelihood of the respondent voting for Clinton relative to the likelihood of voting for Perot. The right column gives coefficients for the effect of each individual characteristic on the relative likelihood of choosing Dole versus choosing Perot. The center column of estimates gives the coefficient estimates for the candidate-specific ideological or issue distances.

\section{Tables 3 and 4 Go Here}

In the ideological distance model (Table 3) we see first that ideological distance is negatively signed and is statistically significant. ${ }^{7}$ This indicates that voters were less likely to support candidates who were further from them ideologically, all other things being equal. In the results for Clinton relative to Perot, we see that a number of other coefficients are statistically significant. Not surprisingly we find that Democrats were more likely to vote for Clinton than Perot; also those who wanted to increase Social Security expenditures and those who were opposed to Dole's tax cut were more likely to support Clinton than Perot. We also find that voters who were pro-choice were more likely to vote for Clinton than were pro-life voters. And, in confirmation of our hypothesis regarding the effects of the national economy on support for Clinton we see that respondents' views on the national economy had a strong effect on support for Clinton relative to Perot.

Turning to the results for Dole support in Table 3, we see that in this specification a similar set of variables were strongly related to Dole support. On one hand we see that Republicans were significantly more likely to support Dole than Perot. We also find that both those who wanted to cut welfare benefits and those who believed that the private sector should supply health care coverage were more likely to support Dole. Last, we find that pro-life voters were significantly more likely to support Dole.

We see very similar results in Table 4 . Here we see that adding the issue distance variables does improve our ability to understand the outcome of the 1996 presidential election; in addition to ideological distance, both opposition to government services and 
opposition to environmental regulation were significant and negatively related to support for Clinton. As to the other substantively important predictors of support for Clinton relative to Perot, we see that in this specification only Democratic partisanship and the perceptions of voters about the state of the national economy are now significantly related to Clinton support relative to Perot. The coefficients on social security, abortion, and the tax cut are no longer significant; and the tax cut coefficient even changes sign. Thus respondents did not necessarily use these issues to distinguish between Clinton and Perot. However, looking at the coefficients for Dole relative to Perot we see that voters did use several of these issues in making their choice among the candidates. For Dole we see that support for welfare cuts, pro-life beliefs, and support for private sector provision of health care are significant predictors of Dole voting. Beside a significant effect for partisanship, we see that the estimated impact of the $15 \%$ tax cut is statistically significant in this specification (significance here is at the $90 \%$ level, with a one-tailed test).

We also see that a respondents' gender has no significant effect on their vote choice once we control for the issues and demographic variables included in our model. This is consistent with recent work showing that the gender gap can be explained by issue positions of voters and candidates, economic perceptions and partisanship (for discussion of this literature see Chaney, Alvarez, and Nagler 1997). This is a much different finding than one would obtain only looking at the bivariate relationship between gender and vote choice in Table 1.

These multinomial probit results also give us one way to assess the different explanations for the 1996 presidential election. We find support first of all for the proposition that the national economy had a strong effect on voter choice in this election. We also find support for the idea that relative spatial location of voters and candidates on ideology and on selected issues (government services and environmental regulation) were significant predictors of candidate support. Last we see that voters' positions on a number of other issues - concerning changes in entitlement policy, in federal government taxation, and abortion policy - were themselves significant predictors of vote choice in the 1996 presidential election.

\subsection{The Magnitude of the Effects of the Independent Variables}

Since these estimated effects in the multinomial probit model translate into individual probabilities of candidate support in a complex and nonlinear manner, we need to transform these coefficient estimates into probabilities to help in our interpretation of the relative magnitude of each type of effect on this election. Thus, we present "first difference" estimates in Table 5. We first set all of the independent variables to their sample mode or mean values. ${ }^{8}$ For each of the independent variables of interest here, we compute predicted probabilities of a voter choosing Clinton, Dole and Perot, for different values of specific independent variables. We first give the estimated probability for the high value of the variable, followed by the same probability of candidate support for the low value of the independent variable. The last entry for each specific independent variable 
is the difference between these two probability estimates. This is a measure of the effect of changes in the variable.

\section{Table 5 Goes Here}

The first two entries in Table 5 show how much more important the state of the national economy was in determining voter choice in 1996 than were perceptions of personal finances. Changes in a respondent's perception of their personal finances produced very slight changes in the probability that the hypothetical voter would support each of the candidates. However, changes in perceptions of the national economy produced very large changes in both Clinton and Dole support. The hypothetical voter was .38 more likely to support Clinton if they saw the national economy as better rather than worse; the hypothetical voter was .31 more likely to support Dole if they saw the national economy as worse, not better.

Next, we see from Table 5 that opinions on cuts in both entitlement programs had strong impacts on candidate support. A voter who wanted to increase either program would be .14 or .08 more likely to support Clinton (Social Security and welfare, respectively). But a voter who wanted to cut either program was more likely to support Dole than a voter who wanted increases in either program (.08 and .18 more likely for Social Security and welfare, respectively). These two issues had less of an impact on voting for Perot, since those wanting cuts in Social Security were more likely to vote for Perot than those wanting increases in that entitlement program; while voters who wanted increases in welfare programs were .10 more likely to vote for Perot than those wanting welfare program cuts.

Dole did receive some support from his $15 \%$ tax cut proposal. Those who favored the tax cut were .12 more likely to support Dole than those who opposed it. Opposing the tax cut led voters to support Clinton by only .07 more than those who supported the tax cut. Similarly, opposing the tax cut led voters to be slightly more likely to support Perot (.05) than those who supported the $15 \%$ tax cut.

Furthermore, both abortion and health insurance beliefs had strong effects in the 1996 election. Pro-choice beliefs made our hypothetical voter .30 more likely to support Clinton than pro-life voters. Pro-life beliefs made voters .33 more likely to support Dole than pro-choice voters. Those who wanted the government to provide health insurance were .12 more likely to support Clinton than those who wanted the private sector to provide health insurance. The opposite relationship is seen for Dole; our hypothetical voter was .25 more likely to vote for Dole if they believed that the private sector should provide health care coverage and not the government.

\section{Effects of Candidate Spatial Locations}

The results presented in Table 5 demonstrated that respondents' views of the issues played a strong role in determining voter choice in the 1996 presidential election. Here 
we want to pursue a different question about the importance of issues in this election by focusing on where the candidates were located on the six issues in our analysis and ideology. We are also interested here in trying to determine what the ideal location was for each candidate on each of these issues and on the ideological scale.

To answer these questions we follow a simulation procedure used by Alvarez and Nagler in their analysis of the 1992 election (Alvarez and Nagler 1995). To determine the effects of candidate behavior with regard to issue and ideological positioning, we simulate the effect of each candidate moving across the issue or ideological space, holding the positions of the other two candidates fixed. In this simulation, we compute the probability of each respondent voting for each of the three candidates as we move the candidate of interest across the issue or ideological space, from 1 to 7 , by increments of .02. We then aggregate the estimated probabilities from all respondents for each candidate at each possible position. This gives us estimated vote shares at each possible position.

We begin our analysis by presenting graphically these results for ideological placements. The results given in Figures 1-3 show the predicted vote share of each candidate (on the vertical axis) as Clinton (Figure 1), Dole (Figure 2) and Perot (Figure 3) are moved across the ideological space. Beginning with Figure 1, what is striking to note is that Clinton actually had a fair amount of flexibility in where he could locate himself in the ideological space. The maximum of his vote share curve occurs when he is located at 4.24 on the seven point scale, where he could have received as high a vote share as $50.3 \%$; however, respondents actually perceived Clinton to be at 3.15 , where he gets $48.7 \%$ of the vote. Thus, while Clinton was not located very far from his ideal ideological position, he could have shifted slightly further to the right and obtained more votes, ceteris paribus. He could have moved as far left as 2.03 before losing the election, holding all else constant.

\section{Figures 1, 2 and 3 go here}

Even more striking, though, are the results presented in Figures 2 (Dole) and 3 (Perot). There we see that neither candidate could have found an ideological position which could have resulted in a different election outcome. Dole was perceived by respondents to be located at 5.15 on this ideological scale, where he received $41.4 \%$ of the vote. We calculate his optimal position to be 4.60 , just slightly to the left of his actual position, where he could have received just a slightly greater vote share (41.7\%). Virtually the same story holds for Perot, since at no ideological position does he come close to even beating Dole. We calculate from our model that Perot's optimal position was 4.36, where he could have received $9.9 \%$ of the total vote - which is equivalent to the $9.9 \%$ of the vote share he obtained from his actual position (4.49).

We performed similar analyses for all of the remaining placement issues. These, as well as the analysis of ideology, are presented in summary form in Table 6 . The first three lines of this table provide a summary of the results for ideology, which we just discussed. The first column of numbers gives each candidate's actual position on ideology or each 
issue. The next column gives the candidate's vote share in our sample. The third column gives the computed position for the candidate to be at where he would maximize his vote share. And the fourth column gives the candidate's predicted vote share if he moved to his optimal position. The final column gives the increase in vote share based on movement to the optimal position.

\section{Table 6 goes here}

We can see from the results in Table 6 that movement on any one issue would not have appreciably helped any of the candidates. Recall that the statistically significant issue distance parameters in our multinomial probit model were government services and environmental regulation. For even these two issues, where we estimated the largest effects on voter preference, it is clear that the candidates were not far from their optimal positions. None of the three candidates could have obtained more that a percentage or two of additional vote share by moving to their optimal position on any of these particular issues.

However, this does not imply that if these three candidates could have determined their optimal position on all of these issues and ideology that they could not have significantly improved their vote shares. In Table 7 we use the optimal placements we just calculated above to determine what the maximal change in vote share would have been if any one of these candidates could have moved to their issue and ideological optimum, ceteris paribus.

\section{Table 7 goes here}

In Table 7 we see that there could have been some dramatic changes in candidate vote shares if each of the candidates had moved to their optimal positions, holding the other candidates constant. Clinton, for example, could have increased his vote share a full five percent by simultaneously moving to his optimal position on all issues and ideology. Also, notice that Dole would have increased his vote share by almost three percent by moving to his optimal location. The biggest increase is seen for Perot, whose vote share would have jumped over five percent had he been able to simultaneously move to his optimal ideological and issue location.

Thus, this evidence leads us to conclude that in general, the election was not determined by the position of the candidates in the ideological and issue space. On an issue-by-issue basis, we could find little support for the idea that any of the candidates were very far from their ideal positions. And when we moved each candidate to their ideological and issue optimal placements simultaneously, we did see some change in the

vote shares of each candidate, but not enough change to have significantly altered the outcome of the 1996 presidential election. 


\section{Effects of the Economy}

This leads us to the other major factor which influenced voter behavior in the 1996 election - economic perceptions. Our methodology gives us the ability to examine another important counterfactual question, following the sort of questions Alvarez and Nagler (1995) asked about the 1992 presidential election. In particular, what if the state of the national economy had been significantly different in 1996? Would Dole have been able to win the 1996 election if voters perceived the national economy and their own personal finances in the same negative light in 1996 as they had in 1992?

In Table 8 we present the frequency of responses to both of the two major survey questions regarding the economy, taken from the 1988, 1992 and 1996 NES. What we find about the aggregate distributions of opinions about personal finances in 1996 is that they were remarkably similar to those in 1988. While the distribution of opinions about changes in personal finance are virtually identical in 1988 and 1996, the assessments of the national economy are, on balance, slightly more favorable in 1996 than in 1988. But what actually is most important to observe about the results in Table 8 is how different 1992 was relative to both 1988 and 1996. There is no question, based on these survey responses, that the electorate was in a sour economic mood in 1992, which is a large part of the story behind Bush's loss (Alvarez and Nagler 1995). The opinions about the change in personal finances are somewhat more negative in 1992 than in either of the other years, but certainly it is clear that the perceptions of the national economy were dramatically different in 1992 than in 1996 or 1988. A full $72 \%$ of American voters believed the national economy had grown worse during the last year of Bush's administration.

\section{Table 8 goes here}

So, while we have found in our multinomial probit results that the national economy had a strong effect in returning Clinton to office in 1996, what would have happened if the economy had been performing poorly in the year leading up to this election? More specifically, what might the results have been if the election in 1996 were held under the same economic conditions which helped to push Clinton to victory in 1992? To provide an answer to this question, we provide counterfactual estimates of candidate vote shares under three different scenarios in Table 9. There, we simulate these hypothetical election outcomes by randomly reassigning opinions of the economy to the 1996 respondents so that the aggregate distributions of opinions about the economy matched the distributions of opinion about the economy held by respondents in 1992. This allows us to compute the probability of voting for each candidate using these hypothetical values for the economic perception variables, and the respondents' actual values for all of the other variables.

\section{Table 9 goes here}

In Table 9 we see that if voters had seen their personal finances in 1996 to be the same as respondents had in 1992 it would not have changed the election outcome. But in the third row of this table, it is clear that had the national economy been seen by voters as being as bad in 1996 as it was in 1992, Clinton would have lost this election by a large margin. Not only could Clinton have lost to Dole by a considerable margin (about 
ten percentage points), Perot's vote share would have risen to just under $15 \%$. Thus, the conclusion is inescapable; just as the weak economy in 1992 doomed the incumbent president to retirement, the strong economy in 1996 granted another incumbent president four more years in office.

\section{The Impact of Candidate Perot}

In 1992, when Perot received roughly $20 \%$ of the popular vote, it was a very important question as to whether his presence in the election campaign hurt Bush more than Clinton. Alvarez and Nagler (1995) showed that Perot drew support from both Bush and Clinton almost equally, taking slightly more votes from Bush than from Clinton. This led them to make a strong substantive claim about the 1992 election, which was that despite the fact that Perot's presence slightly increased Clinton's victory margin, Bush would still have lost the 1992 election. In 1996 Perot captured about 10\% of all the votes cast, which indicates that he was still a considerable force on the national political scene. If these voters had not been presented with a choice of Perot, and if they had still turned out to vote in this election, who would they have cast ballots for? And perhaps more importantly, could Dole have beaten Clinton in a Perot-free political environment?

Our multinomial probit model gives us one way to try to answer this question. We exclude Perot from the choice set by simply computing the two party vote share under the assumption that each voter would simply cast their vote for Clinton or Dole, depending on which candidate they had the greatest utility for. Using this approach, we estimate a two party vote breakdown of $52.4 \%$ for Clinton and $47.6 \%$ for Dole, a margin of just under five percent. Next we reproduce our counterfactual simulations for both issue and economic factors with Perot excluded from the choice set. We examine how much different the two party vote share might have been if each candidate could have positioned themselves at their optimal position (Table 10), and under the scenario that the economy in 1996 was as bad as it was in 1992 (Table 11). In Table 10 we place Clinton at what would be his optimal position on each of the seven issues and ideology - in a two candidate race - and compute the vote shares of Clinton and Dole. We then do the same for Dole. We see that if Clinton were to move to his optimal position on ideology or any of the issues that he would gain a percentage or two over Dole. But, if Clinton were to move simultaneously to his optimal position on ideology and all of the issues he could have swept to a very large victory $(57.1 \%$ to $42.9 \%)$.

\section{Tables 10 and 11 go here}

On an issue--by-issue basis, we also do not see Dole gaining much ground on Clinton. Yet in the end, if Dole had been able to position himself at his optimal position on ideology and all of the issues he could have gotten himself into a $49.7 \%$ versus $50.3 \%$ race. So, without Perot in the mix and by being slightly closer to the median voter on ideology and all of these different issues, Dole could have brought himself to a virtual tie with Clinton. This is much different than the result of the three-way simulations presented in Table 7. 
Next, though, what about the effect of the economy in Perot's absence? We present in Table 11 a counterfactual simulation in which we examine the same three hypothetical scenarios as earlier in this paper (setting the electorate's aggregate economic opinions in 1996 to match those in 1992), but in a situation where Perot is on the sidelines. We see that the effects of personal finances are very slight, just as in the three candidate

race. But we see that were the national economy as bad in 1996 as it was in 1992, and if Perot were not running in the election, Dole would have easily won the 1996 presidential election, by roughly a seven percent margin.

\section{Conclusions and Discussion}

There are at least three policy issues or areas outside of economic performance that have been asserted to have helped reelect Clinton in 1996. First, to the extent that he had an issue based campaign, it is clear that a Democratic tactic was to scare voters into thinking that the Republicans would destroy Social Security. We have no measure of how effective the campaign tactic was in convincing voters of the distinction between the candidates on the issue. But our results fail to show that respondents' views on Social Security had any statistically significant impact on their probability of voting for Clinton - despite the predictable support for Clinton over Dole when we examine the vote choice of voters who support social security in a bivariate comparison.

Second, Clinton ran as a "New Democrat" in 1992, and attempted to sharpen that image for the 1996 race by signing the welfare bill. However, it is clear based on respondents' perception of Clinton's position on the ideological scale that he never really convinced the voters that he was a "New Democrat." And while Clinton could not have moved arbitrarily far to the left on the ideological scale and still won the election, he could have moved quite a bit to the left.

Third, abortion was again a crucial issue distinguishing the Republican and Democratic candidates. A voter's position on abortion was also a major determinant of how they voted. Thus the emergence of the religious right as a force in Republican primary politics has clearly had an impact on presidential elections as the likelihood of the Republicans nominating a candidate who is not pro-life is very slim, and this means that they will continue to send out presidential nominees who hold the minority view on a divisive issue. Our analysis has shown that just as in 1992, the abortion position taken by the Republican presidential candidate clearly is harming their chances for general election victory.

But, simply put, again it was the economy, stupid. The overwhelming impact of the economy in 1992 was not just a fluke, nor was it simply a byproduct of the particularly poor economic circumstances. In 1996 the election was contested under economic circumstances very favorable to the incumbent and voters again relied heavily on their economic perceptions in choosing whom to cast their votes for. Four years into his presidency Clinton had no major legislative victories to peddle; in fact, he had been defeated 
on the centerpiece of his legislative program - health care reform. In office, Clinton had started off pursuing an unpopular proposal on gays in the military, lurched into his health-care defeat, then presided over his party's losing the House for the first time in 40 years, which led to a welfare bill that most people felt he acceded to simply for political expediency. Yet Clinton was still able to easily retain his office.

The dominance of economic perceptions over issues has interesting normative implications for politics. The retrospective model of voting has suggested that voters reward or punish incumbents for economic performance, and that this is a good thing since economic performance is observable and tangible. However, if incumbents have little control over short-term economic performance, voters are choosing candidates essentially at random. This suggests candidates have tremendous freedom to shirk in the policy areas over which they do exert considerable influence. If the economy is good the incumbent will be retained in office. If the economy is bad, having all the correct positions on the issues may not be sufficient to retain the office. Thus, when voters use retrospective evaluations of national economic performance as their primary decision criteria in presidential elections, they might be losing their ability to insure that they eventually achieve the non-economic policy outcomes they desire.

We temper this conclusion with another inference we can draw from our analysis. We have shown that Dole's ability to influence his vote-share by changing his position on the issues was severely limited by the presence of a third candidate (Ross Perot). This suggests that in a "crowded issue space" candidates have little room to maneuver for increased votes. We view examining how this shapes politics in the multiparty democracies of Europe relative to the usual two-party politics of the United States is a crucial area of future research. 


\section{Notes}

${ }^{1}$ In this table we report the row percentages, so while the rows will sum to $100 \%$ the columns will not. Armed with the number of respondents in each cell, interested readers can calculate the column percentages.

${ }^{2}$ We use Bush and Clinton as the candidates in 1994.

${ }^{3}$ Other techniques could be used to estimate a multivariate model of the 1996 presidential election: estimate binomial choice models, ordinal models, or multinomial logit models. Each of these techniques is flawed for estimating models of multicandidate elections (Alvarez 1997; Alvarez and Nagler 1995, 1997).

${ }^{4}$ Below we present results which estimate two of the three free error covariance elements, consistent with the standard results in the literature on the identification of these model parameters (Alvarez and Nagler 1997; Bolduc 1992; Bunch 1991; Keane 1992).

${ }^{5}$ Since the issue placement questions for Perot were asked only to survey respondents in the first two sample replicates, when we calculate the position of Perot on each of these issues we do so using only respondents from these first two sample replicates.

${ }^{6}$ We estimated a model which included only the issue distance parameters but we do not present that here. The results are substantively equivalent.

${ }^{7}$ Both of these multinomial probit models fit the data quite well. The model including issues and ideology produces a predicted three candidate outcome of $48.8 \%$ for Clinton, 41.4\% for Dole and $9.9 \%$ for Perot; the actual estimation sample had a three candidate split of $46.7 \%$ for Clinton, $44.8 \%$ for Dole and $8.4 \%$ for Perot. As for the individual vote predictions, we correctly classified $82.2 \%$ of the voters in our sample. More specifically, of the people who voted for each candidate, we we correctly predicted $83.6 \%$ of the Clinton voters, $81.7 \%$ of the Dole voters, and $50.0 \%$ of the Perot voters. In the model including only ideology (Table 3 ) we estimate one error correlation parameter $\left(\sigma_{C P}\right)$ which is statistically significant at the $\mathrm{p}=.05$ level (one-tailed test). This indicates that the "independence of irrelevant alternatives" assumption is violated in this case (Alvarez and Nagler 1997). However, in the second model (Table 4) we see that this estimated error correlation becomes statistically insignificant, despite begin of almost the same magnitude as in the first multinomial probit model. In the second model, the coefficient on the other error correlation which we estimate $\left(\sigma_{D P}\right)$, while statistically insignificant, drops to near zero. There are two different possible explanations for these different error correlation estimates across the two multinomial probit models. One explanation could be that we have a better specification when we include issues and ideology into our multinomial probit model; it is possible that the information contained in the six issue distance parameters leads to the significant error correlation in the ideology-only model, since this information is excluded from the model in Table 3. The second explanation centers on the fact that we lose 160 cases when we include the six issues in our multinomial 
probit model; the loss of efficiency associated with these missing cases in the second model might produce the larger standard error associated with the estimate of $\sigma_{C P}$ in Table 4 .

${ }^{8}$ Each of the issue and ideological distance variables were set to their sample mean values. We used more substantively plausible values for the other demographic and issue preference variables; the modal respondent was male, older than 60, lived in the south, had a high school education, was politically independent, thought that welfare should be cut but social security should remain constant, saw the national economy as better but their personal finances as unchanged, did not support the Dole $15 \%$ tax cut, was middle-of-the road on government support for health care, and thought that abortion should be permitted only in limited situations. 


\section{References}

Abramowitz, A. I. 1995. "It's Abortion, Stupid: Policy Voting in the 1992 Presidential Election." Journal of Politics 57: 176-186.

Abramson, P. R., J.H. Aldrich, P. Paolino, and D. W. Rohde. 1995. "Third-party and Independent Candidates in American Politics - Wallace, Anderson and Perot." Political Science Quarterly 110: 349-367.

Abramson, P. R., J. H. Aldrich and D. W. Rohde. 1983. Change and Continuity in the 1980 Elections. Rev. ed. Washington, D.C.: Congressional Quarterly Press.

Abramson, P. R., J. H. Aldrich and D. W. Rohde. 1987. Change and Continuity in the 1984 Elections. Rev. ed. Washington, D.C.: Congressional Quarterly Press.

Abramson, P. R., J. H. Aldrich and D. W. Rohde. 1990. Change and Continuity in the 1988 Elections. Washington, D.C.: Congressional Quarterly Press.

Abramson, P. R., J. H. Aldrich and D. W. Rohde. 1994. Change and Continuity in the 1992 Elections. Washington, D.C.: Congressional Quarterly Press.

Alvarez, R. M. 1997. Information and Elections. Ann Arbor: University of Michigan Press.

Alvarez, R. M. and J. Nagler. 1997. "When Politics and Models Collide: Estimating Models of Multicandidate Elections." American Journal of Political Science, forthcoming.

Alvarez, R. M. and J. Nagler. 1995. "Economics, Issues and the Perot Candidacy: Voter Choice in the 1992 Presidential Election." American Journal of Political Science 39: $714-744$.

Bolduc, D. 1992. "Generalized Autoregressive Errors in the Multinomial Probit Model." Transportation Research B 26: 155-70.

Bunch, D. S. 1991. "Estimability in the Multinomial Probit Model." Transportation Research B 25: 1-12.

Carmines, E. C. and J. A. Stimson. 1980. Issue Evolution: Race and the Transformation of American Politics. Princeton: Princeton University Press.

Chaney, C., R. M. Alvarez and J. Nagler. 1997. "Explaining the Gender Gap in U.S. Presidential Elections, 1980-1992." Manuscript, California Institute of Technology.

Fiorina, M. P. 1981. Retrospective Voting in American National Elections. New Haven: Yale University Press. 
Hausman, J. A. and D. A. Wise. 1978. "A Conditional Probit Model for Qualitative Choice: Discrete Decisions Recognizing Interdependence and Heterogeneous Preferences." Econometrica 46: 403-26.

Jackson, John E. 1975. "Issues, Party Choices, and Presidential Votes." American Journal of Political Science 19: 161-86.

Keane, M. P. 1992. "A Note on Identification in the Multinomial Probit Model." Journal of Business and Economic Statistics 10: 193-200.

Key, V. O. 1966. The Responsible Electorate. New York: Vintage.

Kiewiet, D. R. 1983. Macroeconomics and Micropolitics: The Electoral Effects of Economic Issues. Chicago: University of Chicago Press.

Markus, G. B. 1988. "The Impact of Personal and National Economic Conditions on the Presidential Vote: A Pooled Cross-Sectional Analysis." American Journal of Political Science 32: 137-54.

Page, B. I and R. A. Brody. 1982. "Policy Voting and the Electoral Process: The Vietnam War Issue." American Political Science Review 66: 979-95.

Pomper, G. M. 1972. "From Confusion to Clarity: Issues and American Voters, 19561968." American Political Science Review 70: 779-805.

Rosenstone, S. J. 1983. Forecasting Presidential Elections. New Haven: Yale University Press.

Rosenstone, S. J., D. R. Kinder and W. E. Miller. 1997. American National Election Study, 1996 [Computer file]. Conducted by the University of Michigan, Center for Political Studies. Ann Arbor, MI: University of Michigan, Center for Political Studies [producer, distributor].

Tufte, E. R. 1978. Political Control of the Economy. Princeton: Princeton University Press.

Zaller, J. and M. Hunt. 1994. "The Rise and Fall of Candidate Perot - Unmediated Versus Mediated Politics, 1". Political Communication 11: 357-390. 
Table 1: Vote Choice in the 1996 Election

\begin{tabular}{lcccccr} 
& \multicolumn{2}{c}{ Perot } & \multicolumn{2}{c}{ Dole } & \multicolumn{2}{c}{ Clinton } \\
& $\%$ & $\mathrm{~N}$ & $\%$ & $\mathrm{~N}$ & $\%$ & $\mathrm{~N}$ \\
\hline Personal finances & & & & & & \\
Worse & $9.1 \%$ & 23 & $47.2 \%$ & 119 & $43.7 \%$ & 110 \\
Same & $5.8 \%$ & 22 & $43.7 \%$ & 166 & $50.5 \%$ & 192 \\
Better & $7.5 \%$ & 36 & $30.8 \%$ & 148 & $61.8 \%$ & 297 \\
National economy & & & & & & \\
Worse & $13.4 \%$ & 21 & $56.7 \%$ & 89 & $29.9 \%$ & 47 \\
Same & $6.6 \%$ & 31 & $50.1 \%$ & 235 & $43.3 \%$ & 203 \\
Better & $6.0 \%$ & 29 & $22.6 \%$ & 109 & $71.4 \%$ & 345 \\
Party identification & & & & & & \\
Republican & $6.7 \%$ & 32 & $79.3 \%$ & 380 & $14.0 \%$ & 67 \\
Independent & $19.6 \%$ & 11 & $41.1 \%$ & 23 & $39.3 \%$ & 22 \\
Democrat & $6.7 \%$ & 39 & $5.3 \%$ & 31 & $87.9 \%$ & 510 \\
Vote in 1992 & & & & & & \\
Voted & $7.1 \%$ & 72 & $39.6 \%$ & 402 & $53.4 \%$ & 542 \\
Did not vote & $10.5 \%$ & 10 & $31.6 \%$ & 30 & $57.9 \%$ & 55 \\
Gender & & & & & & \\
Men & $8.9 \%$ & 46 & $44.6 \%$ & 230 & $46.5 \%$ & 240 \\
Women & $6.0 \%$ & 36 & $34.0 \%$ & 204 & $60 \%$ & 360 \\
Abortion & & & & & & \\
Pro-life & $7.0 \%$ & 8 & $54.8 \%$ & 63 & $38.3 \%$ & 44 \\
Only rape & $6.8 \%$ & 23 & $52.2 \%$ & 177 & $41 \%$ & 139 \\
When needed & $9.5 \%$ & 17 & $39.1 \%$ & 70 & $51.4 \%$ & 92 \\
Pro-choice & $7.3 \%$ & 34 & $24.8 \%$ & 115 & $67.8 \%$ & 314 \\
Welfare & & & & & & \\
Cut & $7.0 \%$ & 48 & $51.7 \%$ & 353 & $41.3 \%$ & 282 \\
Keep the same & $7.9 \%$ & 26 & $21.5 \%$ & 71 & $70.6 \%$ & 233 \\
Increase & $8.6 \%$ & 8 & $7.5 \%$ & 7 & $83.9 \%$ & 78 \\
Social security & & & & & & \\
Cut & $7.8 \%$ & 6 & $68.8 \%$ & 53 & $23.4 \%$ & 18 \\
Keep the same & $7.7 \%$ & 43 & $44.8 \%$ & 251 & $47.5 \%$ & 266 \\
Increase & $7.0 \%$ & 33 & $26.9 \%$ & 127 & $66.1 \%$ & 312 \\
15\% tax cut & & & & & & \\
Favor & $7.3 \%$ & 82 & $38.9 \%$ & 434 & $53.8 \%$ & 600 \\
\hline
\end{tabular}

Note: Percentages listed are row percentages.

${ }^{a}$ These numbers are based on all respondents who answered each question listed in column one, as well as reporting their vote choice. 
Table 2: Candidate and Voter Ideological Placements

\begin{tabular}{|c|c|c|c|c|}
\hline & 1988 & 1992 & 1994 & 1996 \\
\hline Respondent Self- Placement & 4.37 & 4.21 & 4.22 & 4.33 \\
\hline Republican Candidate $^{a}$ & 5.11 & 5.05 & 5.08 & 5.15 \\
\hline Republican Candidate Distance ${ }^{b}$ & 1.24 & 1.31 & 1.33 & 1.30 \\
\hline Democratic Candidate $^{a}$ & 3.24 & 3.19 & 3.09 & 3.15 \\
\hline Democratic Candidate Distance $^{b}$ & 1.50 & 1.46 & 1.53 & 1.52 \\
\hline $\operatorname{Perot}^{a}$ & & 4.31 & 4.34 & 4.49 \\
\hline Perot Distance ${ }^{b}$ & & 1.15 & 1.18 & 1.16 \\
\hline
\end{tabular}

${ }^{a}$ Mean placement of the candidate by all respondents. In 1994 Bush is the Republican candidate.

${ }^{b}$ Mean distance between respondents and the candidate's mean placement by all respondents. 
Table 3: Multinomial Probit Coefficients, Ideological Distance Model Perot Coefficients Normalized to Zero

\begin{tabular}{|c|c|c|}
\hline \multirow{2}{*}{$\begin{array}{l}\text { Independent } \\
\text { Variables }\end{array}$} & \multicolumn{2}{|c|}{ Coefficients for } \\
\hline & Clinton & Dole \\
\hline \multirow[t]{2}{*}{ Ideological distance } & \multirow{2}{*}{\multicolumn{2}{|c|}{$\begin{array}{c}-.08^{*} \\
.03\end{array}$}} \\
\hline & & \\
\hline \multirow[t]{2}{*}{ Constant } & $-1.67^{*}$ & $-1.30^{* *}$ \\
\hline & .66 & .99 \\
\hline \multirow[t]{2}{*}{ Female } & .12 & $.25^{* *}$ \\
\hline & .14 & .19 \\
\hline \multirow[t]{2}{*}{ Age: $18-29$} & $-.45^{* *}$ & $-.68^{* *}$ \\
\hline & .32 & .52 \\
\hline \multirow[t]{2}{*}{ Age: $30-44$} & $-.61^{*}$ & -.50 \\
\hline & .27 & .42 \\
\hline \multirow[t]{2}{*}{ Age: $45-59$} & -.12 & -.24 \\
\hline & .22 & .22 \\
\hline \multirow[t]{2}{*}{ West } & $.30^{* *}$ & -.14 \\
\hline & .21 & .19 \\
\hline \multirow[t]{2}{*}{ South } & .17 & -.13 \\
\hline & .18 & .17 \\
\hline \multirow[t]{2}{*}{ East } & .26 & $-.40^{* *}$ \\
\hline & .25 & .27 \\
\hline \multirow[t]{2}{*}{ Increase Welfare } & .09 & $-.45^{*}$ \\
\hline & .16 & .27 \\
\hline \multirow[t]{2}{*}{ Increase Social Security } & $.32 *$ & .03 \\
\hline & .13 & .12 \\
\hline \multirow[t]{2}{*}{ Education } & .40 & $1.95^{*}$ \\
\hline & .84 & 1.35 \\
\hline \multirow[t]{2}{*}{ Personal Finance Improved } & .04 & .08 \\
\hline & .10 & .12 \\
\hline \multirow[t]{2}{*}{ National Economy Improved } & $.50^{*}$ & -.20 \\
\hline & .18 & .17 \\
\hline \multirow[t]{2}{*}{ Democrat } & $1.09^{*}$ & $-.81^{* *}$ \\
\hline & .46 & .50 \\
\hline \multirow[t]{2}{*}{ Republican } & -.07 & $.72^{* *}$ \\
\hline & .44 & .52 \\
\hline \multirow[t]{2}{*}{ Pro-Choice Abortion } & $.15^{* *}$ & $-.23^{* *}$ \\
\hline & .11 & .16 \\
\hline \multirow[t]{2}{*}{ Approve $15 \%$ Tax Cut } & $-.27 * *$ & .28 \\
\hline & .19 & .26 \\
\hline \multirow[t]{2}{*}{ Oppose Govt Health Ins } & -.02 & $.15^{* *}$ \\
\hline & .07 & .10 \\
\hline \multirow[t]{2}{*}{$\sigma_{D P}$} & \multicolumn{2}{|c|}{.55} \\
\hline & \multicolumn{2}{|c|}{.59} \\
\hline$\sigma_{C P}$ & & \\
\hline & & \\
\hline Number of Observations & & \\
\hline Log Likelihood & & .08 \\
\hline
\end{tabular}

* Significant at $\mathrm{p}=.05$ level (1-tailed test)

** Significant at $\mathrm{p}=.10$ level (1-tailed test). 
Table 4: Multinomial Probit Coefficients, Issue and Ideological Distance Model Perot Coefficients Normalized to Zero

\begin{tabular}{|c|c|c|}
\hline Independent & Coeffic & nts for \\
\hline Variables & Clinton & Dole \\
\hline Gov't services & & \\
\hline & & \\
\hline Defense spending & & \\
\hline & & \\
\hline Gov't jobs & & \\
\hline & & \\
\hline Aid to blacks & & \\
\hline & & \\
\hline Crime reduction & & \\
\hline & & \\
\hline Environmental regulation & & \\
\hline & & \\
\hline Ideology & & \\
\hline & & \\
\hline Constant & $-2.78^{*}$ & $-1.80^{* *}$ \\
\hline & 1.28 & 1.27 \\
\hline Female & .11 & .33 \\
\hline & .20 & .26 \\
\hline Age: $18-29$ & $-.80^{*}$ & $-.97^{* *}$ \\
\hline & .48 & .62 \\
\hline Age: $30-44$ & $-1.06^{*}$ & $-.65^{* *}$ \\
\hline & .38 & .48 \\
\hline Age: $45-59$ & -.33 & -.28 \\
\hline & .28 & .33 \\
\hline West & $.40^{* *}$ & .10 \\
\hline & .29 & .34 \\
\hline South & .27 & -.13 \\
\hline & .24 & .28 \\
\hline East & .22 & -.44 \\
\hline & .30 & .36 \\
\hline
\end{tabular}


Table 4 continued

Multinomial Probit Coefficients, Issue and Ideological Distance Model

Perot Coefficients Normalized to Zero

Independent Coefficients for

Variables Clinton Dole

\begin{tabular}{lcc}
\hline Increase Welfare & -.11 & $-.45^{*}$ \\
Increase Social Security & .17 & .25 \\
Education & .23 & .03 \\
Personal Finance Improved & .19 & .20 \\
& 1.20 & $2.56^{*}$ \\
National Economy Improved & .09 & 1.40 \\
& $.57^{*}$ & .16 \\
Democrat & .28 & .18 \\
\multirow{2}{*}{ Republican } & $1.16^{*}$ & -.21 \\
& .65 & .23 \\
Pro-Choice Abortion & .51 & $-.98^{* *}$ \\
Approve $15 \%$ Tax Cut & .56 & .61 \\
& .11 & $.99^{* *}$ \\
Oppose Govt Health Ins & .15 & .70 \\
$\sigma_{D P}$ & .11 & $-.32^{*}$ \\
$\sigma_{C P}$ & .31 & .19 \\
Number of Observations & .05 & $.49^{* *}$ \\
Log Likelihood & .08 & .35 \\
\hline
\end{tabular}

* Significant at $\mathrm{p}=.05$ level (1-tailed test)

** Significant at $\mathrm{p}=.10$ level (1-tailed test). 
Table 5: Effects of Economics and Issues in 1996 Probability of Voting for

\begin{tabular}{lccc} 
& Clinton & Dole & Perot \\
\hline Personal finance & & & \\
Better & .49 & .39 & .11 \\
Worse & .50 & .34 & .16 \\
Difference & -.01 & .05 & -.05 \\
National economy & & & \\
Better & .49 & .37 & .14 \\
Worse & .11 & .68 & .21 \\
Difference & .38 & -.31 & -.07 \\
Social security & & & \\
Increase & .56 & .33 & .11 \\
Cut & .42 & .41 & .17 \\
Difference & .14 & -.08 & -.06 \\
Welfare & & & \\
Increase & .57 & .19 & .24 \\
Cut & .49 & .37 & .14 \\
Difference & .08 & -.18 & .10 \\
15\% tax cut & & & \\
Favor & .42 & .49 & .09 \\
Oppose & .49 & .37 & .14 \\
Difference & -.07 & .12 & -.05 \\
Abortion & & & \\
Pro-choice & .59 & .27 & .14 \\
Pro-life & .29 & .60 & .11 \\
Difference & .30 & -.33 & .03 \\
Health insurance & & & \\
Government & .54 & .25 & .21 \\
Private sector & .42 & .50 & .08 \\
Difference & .12 & -.25 & .13 \\
Baseline Probability & .49 & .37 & .14 \\
\hline
\end{tabular}

Estimated probabilities were calculated with the other variables set to their mean or mode value. 
Table 6: Vote Shares and Optimal Spatial Locations

\begin{tabular}{llccccc}
\multicolumn{1}{c}{ Issue } & Candidate & $\begin{array}{c}\text { Actual } \\
\text { Position }\end{array}$ & $\begin{array}{c}\text { Actual } \\
\text { Vote }\end{array}$ & $\begin{array}{c}\text { Optimal } \\
\text { Position }\end{array}$ & $\begin{array}{c}\text { Optimal } \\
\text { Vote }\end{array}$ & $\begin{array}{c}\text { Vote } \\
\text { Increase }\end{array}$ \\
\hline Ideology & Clinton & 3.15 & $48.7 \%$ & 4.24 & $50.3 \%$ & $0.6 \%$ \\
& Dole & 5.15 & $41.4 \%$ & 4.60 & $41.7 \%$ & $0.3 \%$ \\
Gov't services & Perot & 4.49 & $9.9 \%$ & 4.36 & $9.9 \%$ & $0.0 \%$ \\
& & & & & & \\
& Clinton & 4.91 & $48.7 \%$ & 3.88 & $49.6 \%$ & $0.9 \%$ \\
& Dole & 3.15 & $41.4 \%$ & 3.52 & $41.5 \%$ & $0.1 \%$ \\
Defense spending & Perot & 2.94 & $10.1 \%$ & 3.76 & $10.3 \%$ & $0.2 \%$ \\
& & & & & & \\
& Clinton & 3.95 & $48.8 \%$ & 4.00 & $48.8 \%$ & $0.0 \%$ \\
Jobs & Dole & 4.65 & $41.4 \%$ & 4.12 & $41.5 \%$ & $0.1 \%$ \\
& Perot & 3.83 & $9.9 \%$ & 3.88 & $10.1 \%$ & $0.2 \%$ \\
& & & & & & \\
Aid to blacks & Clinton & 3.27 & $48.7 \%$ & 4.48 & $49.1 \%$ & $0.4 \%$ \\
& Dole & 5.09 & $41.4 \%$ & 4.90 & $41.4 \%$ & $0.0 \%$ \\
& Perot & 5.20 & $9.9 \%$ & 4.60 & $10.0 \%$ & $0.1 \%$ \\
& & & & & & \\
Crime reduction & Clinton & 3.32 & $48.7 \%$ & 4.84 & $49.1 \%$ & $0.4 \%$ \\
& Dole & 5.00 & $41.4 \%$ & 5.20 & $41.4 \%$ & $0.0 \%$ \\
& Perot & 2.26 & $9.9 \%$ & 5.08 & $11.0 \%$ & $1.1 \%$ \\
& & & & & & \\
& Clinton & 3.70 & $48.7 \%$ & 1.00 & $49.9 \%$ & $1.2 \%$ \\
& Dole & 5.10 & $41.4 \%$ & 1.00 & $42.6 \%$ & $1.2 \%$ \\
& Perot & 5.10 & $9.9 \%$ & 1.00 & $11.1 \%$ & $1.2 \%$ \\
& & & & & & \\
& Clinton & 3.24 & $48.7 \%$ & 3.40 & $48.7 \%$ & $0.0 \%$ \\
& Dole & 4.57 & $41.4 \%$ & 3.52 & $42.5 \%$ & $1.1 \%$ \\
& Perot & 4.73 & $9.9 \%$ & 3.28 & $18.8 \%$ & $8.9 \%$ \\
\hline
\end{tabular}

Table 7: Estimated Vote Shares with Candidates at Optimal Locations on All Issues and Ideology

\begin{tabular}{lccc} 
& \multicolumn{3}{c}{ Candidate Vote Shares } \\
\cline { 2 - 4 } & Clinton & Dole & Perot \\
\hline Clinton at Optimal Position & 53.7 & 37.8 & 8.3 \\
Dole at Optimal Position & 46.8 & 43.8 & 9.3 \\
Perot at Optimal Position & 44.9 & 40.1 & 15.1 \\
Actual Positions & 48.7 & 41.4 & 9.9 \\
\hline
\end{tabular}


Table 8: Comparative Economic Opinions, 1988-96 Personal finances

\begin{tabular}{lcccccc}
\cline { 2 - 6 } Opinion & \multicolumn{2}{c}{1988} & \multicolumn{2}{c}{1992} & \multicolumn{2}{c}{1996} \\
\cline { 2 - 7 } & $\mathrm{N}$ & Percent & $\mathrm{N}$ & Percent & $\mathrm{N}$ & Percent \\
\hline Better & 849 & 42.4 & 749 & 30.3 & 747 & 43.8 \\
Same & 664 & 32.8 & 866 & 35.0 & 542 & 31.8 \\
Worse & 502 & 24.8 & 859 & 34.7 & 418 & 24.5 \\
\hline
\end{tabular}

\begin{tabular}{lcccccc} 
& \multicolumn{6}{c}{ National economy } \\
\cline { 2 - 7 } Opinion & \multicolumn{1}{c}{1988} & \multicolumn{2}{c}{1992} & \multicolumn{2}{c}{1996} \\
\cline { 2 - 7 } & $\mathrm{N}$ & Percent & $\mathrm{N}$ & Percent & $\mathrm{N}$ & Percent \\
\hline Better & 368 & 18.8 & 113 & 4.6 & 670 & 39.5 \\
Same & 978 & 50.0 & 567 & 23.1 & 746 & 43.9 \\
Worse & 610 & 31.2 & 1777 & 72.3 & 282 & 16.6 \\
\hline
\end{tabular}

Table 9: Comparative Economic Opinion Effects, 1992-96

\begin{tabular}{lccc} 
& \multicolumn{3}{c}{ Candidate Vote Shares } \\
\cline { 2 - 4 } Distribution of Respondents' Perceptions of Economy & Clinton & Dole & Perot \\
\hline 1996 Baseline & 48.7 & 41.4 & 9.9 \\
1992 Personal finances Only & 48.6 & 41.2 & 10.1 \\
1992 National economy Only & 37.7 & 47.8 & 14.5 \\
1992 Personal finances and National Economy & 37.4 & 47.7 & 14.9 \\
\hline
\end{tabular}


Table 10: Two Party Vote Shares at Optimal Spatial Locations Candidate vote shares

\begin{tabular}{lcc} 
& Clinton & Dole \\
\cline { 2 - 3 } Clinton at optimum: & 54.2 & 45.8 \\
Ideology & 53.3 & 46.7 \\
Gov't services & 53.0 & 47.1 \\
Defense spending & 52.7 & 42.3 \\
Jobs & 53.2 & 46.8 \\
Aid to blacks & 53.7 & 46.3 \\
Crime reduction & 52.4 & 47.3 \\
Environmental regulation & 57.1 & 42.9 \\
All issues & & \\
Dole at optimum: & 52.0 & 48.0 \\
Ideology & 52.2 & 47.8 \\
Gov't services & 52.2 & 47.8 \\
$\quad$ Defense spending & 52.4 & 47.6 \\
Jobs & 52.3 & 47.7 \\
Aid to blacks & 52.0 & 48.0 \\
Crime reduction & 52.0 & 48.1 \\
$\quad$ Environmental regulation & 52.3 & 49.7 \\
All issues & 50.3 & \\
$\quad$ Baseline two party vote share & 52.4 & 47.6 \\
\hline
\end{tabular}

Table 11: Two Party Vote Shares Under Different Economic Conditions

\begin{tabular}{lcc} 
& \multicolumn{2}{c}{ Candidate vote shares } \\
\cline { 2 - 3 } Comparison & Clinton & Dole \\
\hline Personal finances only & 52.6 & 47.4 \\
National economy only & 46.6 & 53.4 \\
Both & 46.4 & 53.6 \\
Baseline & 52.4 & 47.6 \\
\hline
\end{tabular}


Figure 1

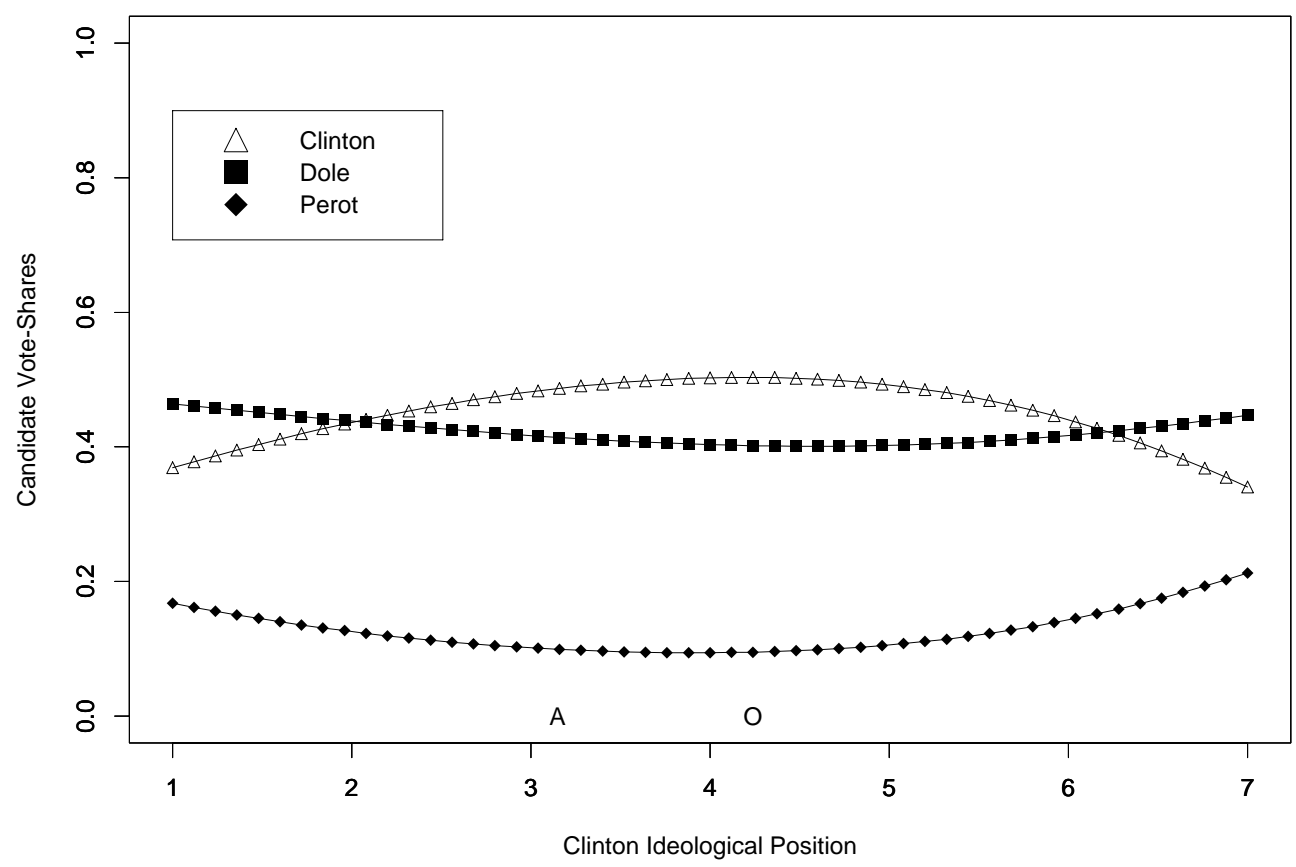

Note: "A" stands for Clinton's Actual position on the ideological scale; "O" stands for Clinton's estimated Optimal position on the ideological scale. 
Figure 2

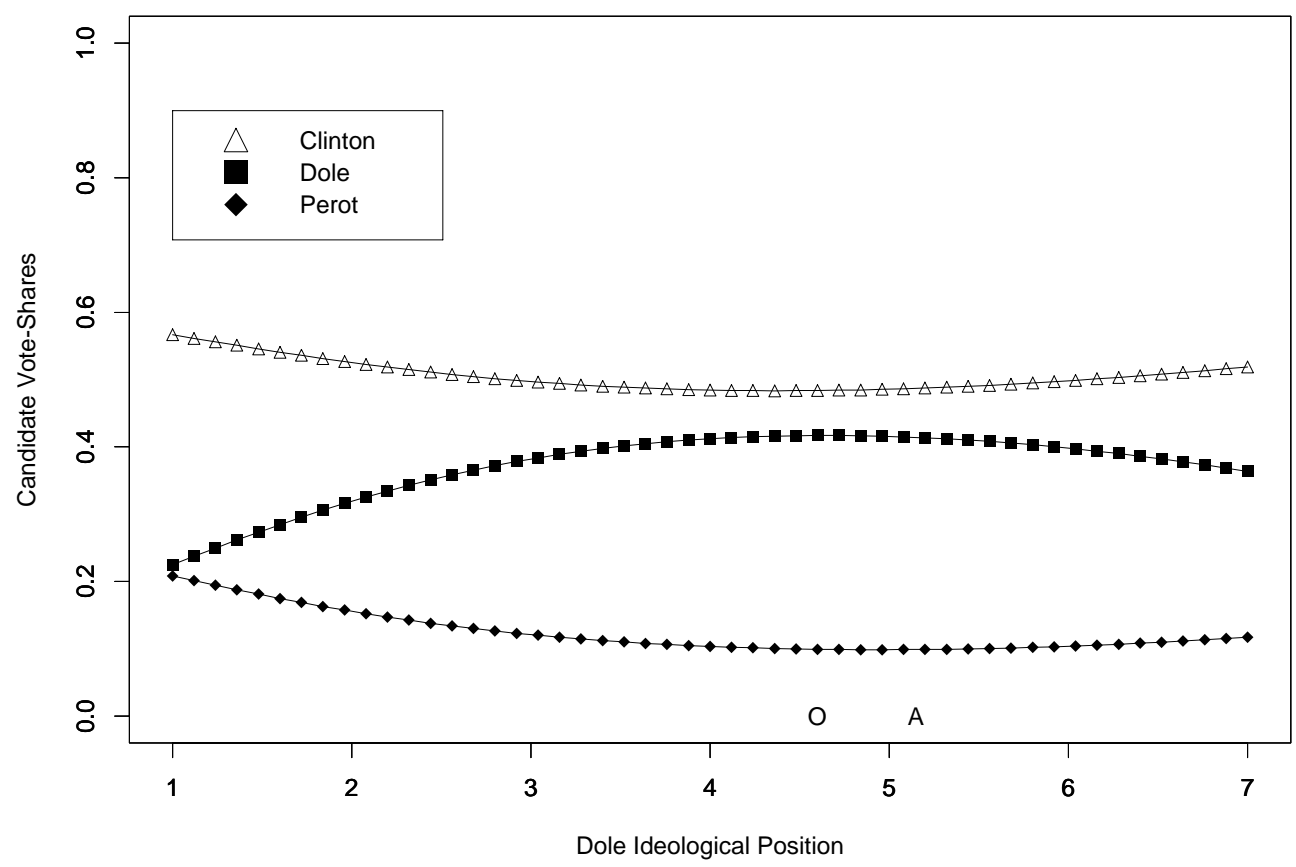

Note: "A" stands for Clinton's Actual position on the ideological scale; "O" stands for Clinton's estimated Optimal position on the ideological scale. 
Figure 3

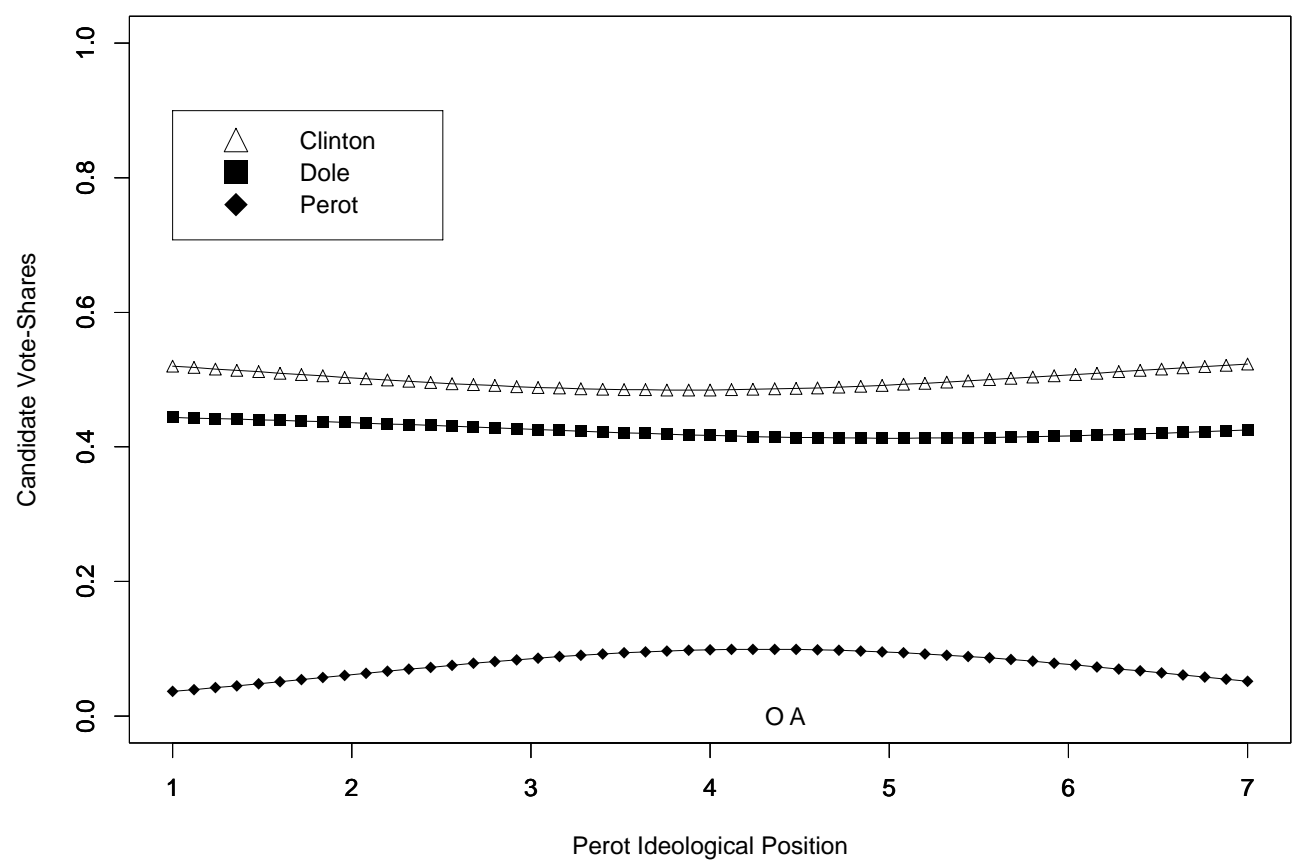

Note: "A" stands for Clinton's Actual position on the ideological scale; "O" stands for Clinton's estimated Optimal position on the ideological scale. 